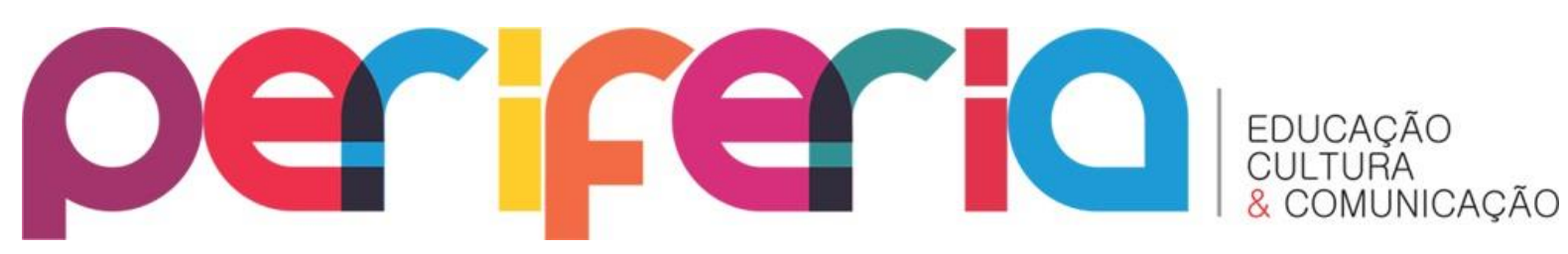

\title{
A EXPERIÊNCIA TRANSEXUAL: ESTIGMA, ESTEREÓTIPO E DESQUALIFICAÇÃO SOCIAL NO INTRAMUROS DA ESCOLA
}

\author{
Denise da Silva Braga ${ }^{1}$ \\ Centro Universitário de Belo Horizonte
}

\section{RESUMO}

Como os discursos escolares sobre as sexualidades são percebidos por sujeitos transexuais? E como tais discursos repercutem nos seus processos de identificação e de produção de si? Neste texto, a partir das narrativas de três mulheres transexuais, busco analisar repercussões das práticas escolares e dos discursos sobre as sexualidades nos sentidos incorporados mediante a experiência de viver a diferença enunciada pelo olhar normalizador das instituições de controle. Interessa evidenciar que os sujeitos transexuais produzem suas próprias histórias, mesmo estando às margens dos discursos socialmente legitimados que circulam na escola, no interior de um discurso normalizador cuja pretensão é manter a hegemonia da história universal, onde apenas alguns sujeitos são inscritos e reconhecidos sob a denominação de humanos.

Palavras-chave: sexualidade, transexualidade, experiência escolar.

TRANSSEXUAL EXPERIENCE: STIGMA, STEREOTYPE AND SOCIAL DISQUALIFICATION INSIDE THE SCHOOL WALLS

\section{ABSTRACT}

As the school discourses on sexuality are perceived by subjected transsexuals? And as such speeches affect the processes of identification and production of itself? In this paper, based on the narratives of three transsexuals women, I try to analyze impact of school practices and discourses on sexuality incorporated the experience of living the difference enunciated by the normalizer look of control institutions. Matter show that, even outside of the legitimated discourses at school - one discourse whose claim is to maintain the hegemony of universal history in which only a few individuals are recognized and enrolled under the name of human the individuals transsexuals produce its own stories.

Keywords: sexuality, transexuality, school experience.

\footnotetext{
${ }^{1}$ Doutora em educação pela Universidade do Estado do Rio de Janeiro. Professora do Centro Universitário de Belo Horizonte - UNIBH. E-mail: denise.sbraga@yahoo.com.br
} 


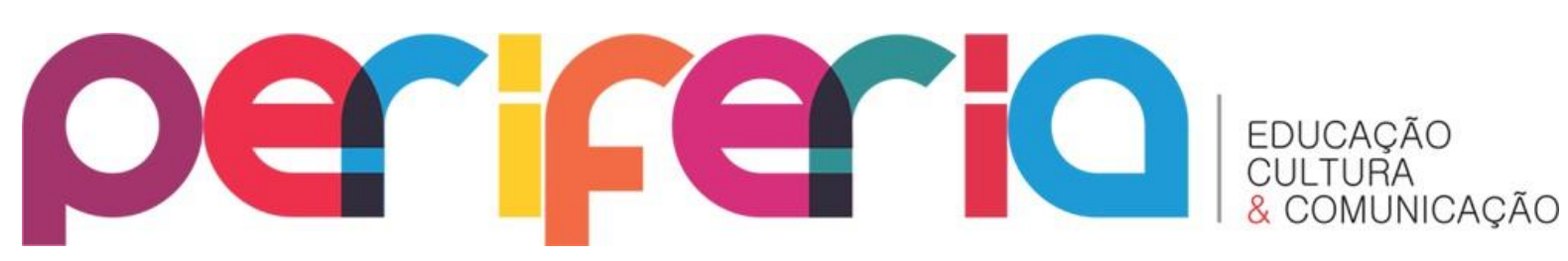

\section{INTRODUÇÃO}

A emergência das novas/outras identidades nas cenas contemporâneas coloca em evidência o processo de descentração do sujeito - até então negado pela ideia do sujeito unificado e estável da modernidade. Esta perda do "sentido de si" desloca os indivíduos tanto de seu lugar no mundo social e cultural quanto de si mesmos e constitui o que se convencionou chamar de "crise de identidade" (HALL, 2002), desalojando os sujeitos das posições anteriormente reconhecidas e possíveis para uma experiência de viver com/na diferença, na qual os sentidos de si e do outro são cambiantes, um vir a ser sempre adiado. Com a volatilização do sentido de identidade, as classificações estáveis, a partir das quais a realidade se tornava reconhecível e familiar aos indivíduos modernos, cedem lugar a um intrincado jogo de identificações provisórias e instáveis, forjando um novo espaço social visivelmente marcado por um eventual sentimento de ausência de referência (CARVALHO, 2003).

Nesta cena atual, na qual proliferam as possibilidades identitárias e se acentua a diferença, a realidade social se evidencia como um espaço-tempo híbrido, de invenções e de negociações; uma dinâmica na qual a hibridização das próprias identidades amplia o leque das "vidas possíveis". Vidas estas que se produzem nas condições mais adversas e, frequentemente, figuram como indesejáveis nos espaços sociais nos quais suas identificações são constituídas, sobremaneira nas instituições sociais altamente reguladas - como é o caso da escola. Nestes contextos, se evidenciam indagações que justificam questionar: como se produzem no espaço normalizado da escola sujeitos cuja materialidade corpórea desestabiliza a própria norma? 


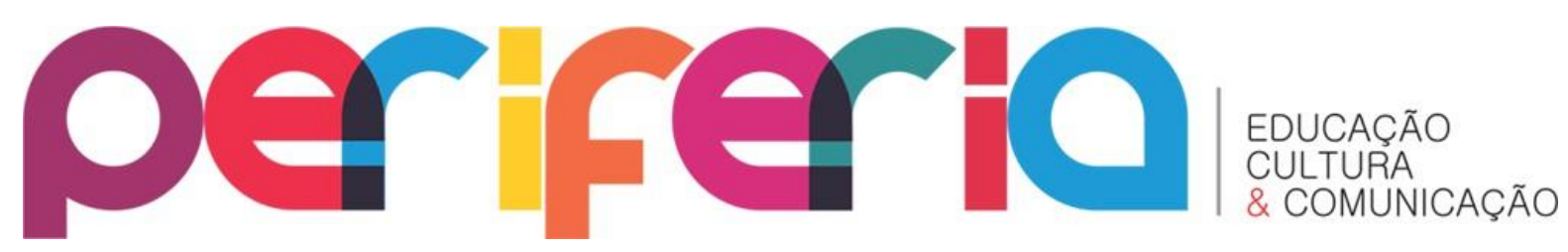

\section{VIDAS “FORA DA NORMA": ESTIGMA, ESTEREÓTIPO E ABJEÇÃO}

Aliadas aos processos individuais de produção de si, as possibilidades ampliadas de comunicação permitem visibilizar modos de vida, sentidos e significados capturados e/ou produzidos nas/das relações sociais e fomentam a tessitura de novos/outros discursos, de novos modos de ser, de novas identidades. Dessa forma, neste espaço social pouco demarcado, constituído e tangenciado pelas relações de poder, diferentes sujeitos negociam formas de pertencimento: como inscrever-se como sujeito no sistema de significação social? Evocando a perspectiva foucaultiana, opero com a ideia do sujeito como aquilo que dele se diz, um sujeito que se constitui como efeito de práticas discursivas. Nessa acepção o discurso não se resume ao mero ato da fala ou mesmo ao ato enunciativo, nem se fixa em um campo de exterioridade em relação aos objetos dos quais trata, antes se constitui como uma prática que forma sistematicamente os objetos dos quais fala (FOUCAULT, 2000, p.56).

Assim, as subjetividades são produzidas ao mesmo tempo em que produzem as relações sociais, como efeito das experiências do sujeito e das suas relações com outros sujeitos, com as coisas e com o mundo e, portanto, a repetição de discursos sobre o outro, possibilita a criação e a divulgação de representações da realidade e a demarcação de zonas de pertencimento capazes de fixar posições como desejáveis ou indesejáveis. Para passar como se fosse natural, essa operação "requer a produção de diferenciações, individuações, efeitos de identidade através das quais as práticas discriminatórias podem mapear populações sujeitas" (BHABHA, 2007, p.161).

Populações que se encontram fora dos limites da inteligibilidade social são mais facilmente capturadas pelas práticas reiterativas de discriminação e de exclusão dos discursos hegemônicos que constituem a "normalidade" do mundo social. Ausentes da linguagem, esses sujeitos têm negado o seu pertencimento ao mundo social e não podem existir, senão como figuras monstruosas, ameaçadoras: abjeções. Butler (2003) trata como abjetos os corpos cuja materialidade é considerada como "não importante", "pessoas que vivem em paradoxos identitários [e] estão sujeitas ao não 


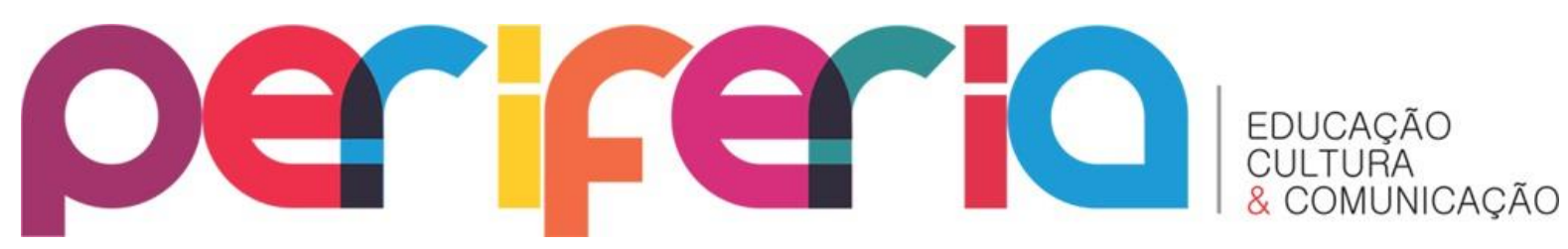

reconhecimento por manterem uma relação crítica com as normas e, portanto, serem consideradas menos humanas do que as 'ajustadas', as 'normais'”' (PINO, 2007, p.165).

Os sujeitos marcados como abjetos são constantemente ameaçados de serem invisibilizados e desfeitos, expurgados do que se entende como ser humano. Por se encontrarem "fora da norma" esses sujeitos experienciam corpos negados e/ou invisibilizados e, não raramente, são vistos com terror, pois a sua "estranha materialidade" evidencia o caráter inventado, cultural e instável de todas as identidades e sugere concreta e simbolicamente possibilidades de proliferação e de multiplicação das formas de existir - dentro, fora e sobre as fronteiras que demarcam as "vidas possíveis".

Nas narrativas que compõem este texto, o corpo do(a) transexual, fabricado sob o olhar normalizador e como efeito das enunciações e práticas educativas das instituições de controle social, carrega a marca da abjeção. Essa abjeção se concretiza na experiência dos corpos em transformação que já não são compatíveis com a certidão de nascimento e, tampouco, alcançaram a feminilidade almejada; nas enunciações de si que misturam o gênero nos pronomes, tentando dar conta de um movimento de tornar-se aquele(a) que fala; nos efeitos da presença transexual nas relações sociais mediante as representações negativas que operam em regimes de verdade, como um discurso que a sociedade acolhe e faz funcionar como verdadeiro (FOUCAULT, 2004). O que as experiências desses sujeitos nos mostram é que não há como controlar os efeitos que tais "verdades" produzem na sua subjetividade, o modo como afetam seus processos de identificação, principalmente quando isso os desaloja de determinada posição humana para outra hierarquicamente inferior.

Os processos de construção do estigma estão associados às formas como alguns atributos dos indivíduos passam a ser considerados socialmente desqualificantes ou indesejáveis. A desqualificação é, em geral, fabricada a partir dos deslizamentos que se dão em relação aos modelos pré-estabelecidos, como "desvios" das normas que visam manter em operação padrões sociais hegemônicos e conter a diferença. Frequentemente esses sujeitos, cujas vidas são alvo de estranhamentos, 


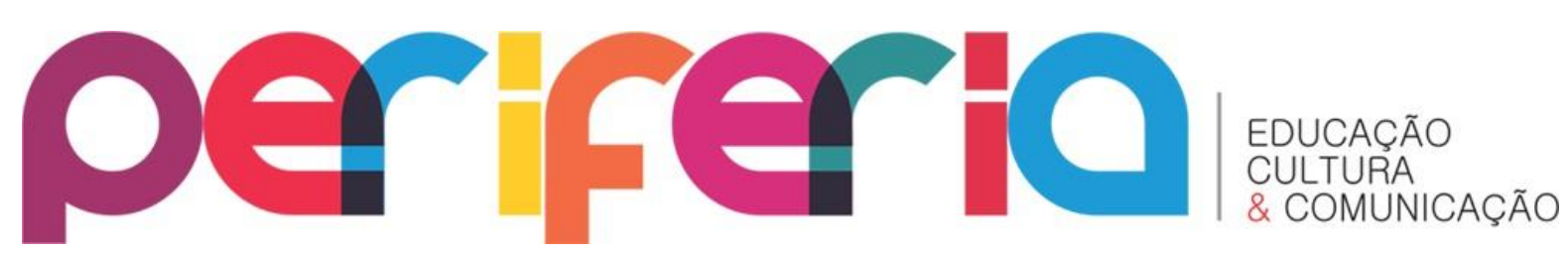

passam a integrar o mundo social a partir de estereótipos. Segundo Bhabha (2007), o estereótipo é uma simplificação porque é uma forma fixa de representação que nega a diferença, uma construção antecipada, uma montagem ingênua da diferença que autoriza a discriminação. O estereótipo, como estratégia discursiva, opera primordialmente no sentido de fixar a diferença e impedir a agência do outro e, para tanto, requer a repetição contínua das mesmas histórias sobre esse outro monstruoso e ameaçador cuja "diferença negativa" será sempre conhecida de antemão.

Nesse sentido, mais do que "dar voz" às culturas historicamente negadas ou silenciadas nos diversos textos sociais, é importante reconhecer a ambivalência inerente aos estereótipos que circulam e se propagam no espaço-tempo escolar como possibilidade de agência sobre os seus efeitos.

\section{SER O OUTRO: A EXPERIÊNCIA TRANSEXUAL NO ESPAÇO-TEMPO DA ESCOLA}

Ausentes do discurso como sujeitos cujas histórias interessam politicamente e restritas às representações naturalizadas que circulam nos meios sociais e que são facilmente incorporadas, as experiências transexuais figuram no currículo escolar como algo inexistente ou sem valor, cujo vínculo à "categoria humana" se dá, quase exclusivamente, pela ideia de algo que a transgride. Dessa forma as representações da transexualidade (e das transexuais) que figuram no espaço social comum são produzidas sobre um "outro" a quem não se conhece ou não interessa conhecer.

Veiga Neto (2002) afirma que a criação do currículo contribuiu para um novo enfoque sobre tempo e espaço na escola e para a instituição de novas articulações entre esses elementos. Segundo o autor, "O currículo imprimiu uma ordem geométrica, reticular e disciplinar, tanto aos saberes quanto à distribuição desses saberes ao longo de um tempo" (VEIGA-NETO, 2002, p.164) - um uso minuciosamente controlado do tempo, em espaços rigidamente organizados e vigiados, de modo a estabelecer fronteiras e favorecer a classificação, a hierarquização 


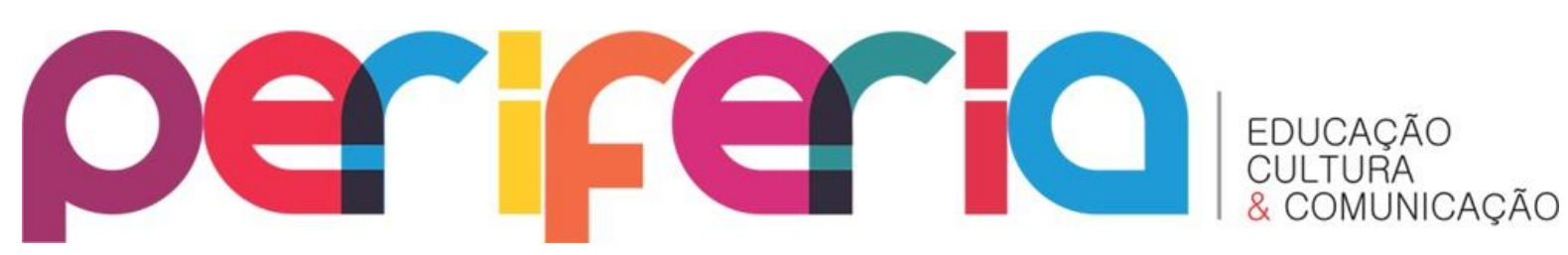

e o isolamento dos indivíduos - geralmente os "pouco úteis", "improdutivos" ou "indesejáveis" - que as classificações permitiram transformar em outro.

Nesse sentido,

[...] o currículo funcionou - e certamente ainda funciona - como o grande dispositivo pedagógico que recolocou (...) o limite a partir do qual os outros passam a existir para nós, o limite a partir do qual a diferença começa a se fazer problema para nós. Em suma, o currículo contribuiu - e ainda contribui - para fazer do outro o diferente e, por isso, um problema ou um perigo para nós (VEIGA-NETO, 2002, p. 165, grifo do autor).

O currículo está, desde sua origem, intrinsecamente ligado a um projeto social e pode ser entendido, portanto, como um "artefato sociocultural", fabricado a partir do conhecimento "considerado socialmente válido" (GOODSON, 2003). Dito de outra forma, o alcance e os limites de um currículo estão sempre modulados pelas contingências e pelos sujeitos com os quais precisa operar. O currículo pode ser visto como um mecanismo e um instrumento de poder no qual se produzem regras e padrões de verdade para guiar e governar os sujeitos. Dessa maneira, e por meio da forma de organização dos conhecimentos e dos tempos-espaços escolares, se constroem sistemas de significação e conhecimentos especializados que permitam administrar as formas de pensar e de agir dos sujeitos, isto é, o seu "eu".

Nesse sentido, a escola reafirma uma disposição repressiva (na acepção foucaultiana), segundo a qual a repressão não deve ser lida apenas como proibição ou impedimento da ação, antes, como uma ação produtora de discursos que, nesse caso, formatam corpos e corporalidades. Entretanto, estas questões não são novas: muito já se estudou das implicações do currículo como dispositivo de manutenção da ordem, como estratégia de colonização de poderes e de saberes. De forma muito apropriada, Goodson (2003, p.78) argumenta que "(...) a elaboração do currículo pode ser considerada um processo pelo qual se inventa tradição" e, apoiando-se em Hobsbawn, define "tradição inventada" como tradições que tanto podem ser realmente "inventadas, construídas e formalmente instituídas", quanto podem emergir de modo menos definível, em um período de tempo curto e datável e se estabelecer 


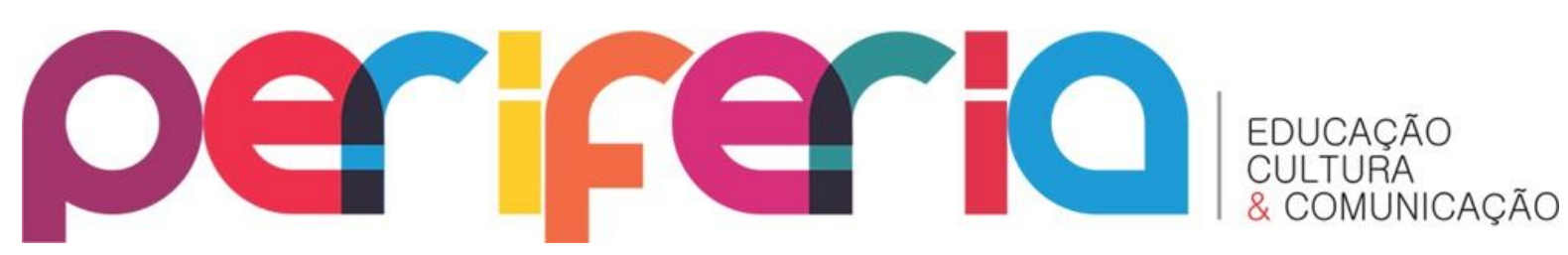

rapidamente (GOODSON, 2003, p.77). Ainda citando Hobsbawn, o autor assim define a questão:

Tradição inventada significa um conjunto de práticas e ritos: práticas, normalmente regidas por normas expressas ou tacitamente aceitas: e ritos - natureza simbólica - que procuram fazer circular certos valores e normas de comportamento mediante repetição, que implica automaticamente continuidade com o passado. De fato, onde é possível, o que tais práticas e ritos buscam é estabelecer a continuidade com um passado apropriado (HOBSBAWN; RANGER apud GOODSON, 2003, p.78).

Destarte, o que se evidencia é uma engenharia escolar profundamente marcada na/pela tradição, resultante do projeto de sujeito que as expectativas sociais configuram, do "dever ser" que ultrapassa os limites do espaço-tempo da escola e se impõe como força de repetição e de prescrição de identidade. O que espero acrescentar à discussão é que essa repetição não se dá de forma linear, pois, se a tradição está imbricada no sentido da própria escola que se produziu no decurso da história e do projeto de continuidade das relações sociais, também existe a possibilidade da recriação nessa repetição, uma vez que, embora a tentativa seja de perpetuar o mesmo, na própria dinâmica da enunciação, outros sentidos são ditos, traduzidos, interpretados, produzidos. Ou seja, ainda que a tradição seja o pilar sob o qual se organiza o currículo; como um "artefato cultural" ele não apenas reproduz, mas recria (em um mesmo tempo) cultura(s).

Lidar com a noção do currículo como cultura pressupõe, nesta lógica, redimensionar o currículo - e retraduzir a própria noção de cultura (ora entendida como lugar de enunciação e não mais como um repertório partilhado de significados) - implica, então, pensá-lo como um "híbrido cultural”, um “(...) espaço-tempo de fronteira (...) práticas ambivalentes que incluem o mesmo e o outro num jogo em que nem a vitória nem a derrota jamais serão completas" (MACEDO, 2006, p.289).

Assim como Macedo (2006), entendo que, nessa dimensão, o currículo se constitui:

[...] como um espaço-tempo em que estão mesclados os discursos da ciência, da nação, do mercado, os "saberes comuns", as 


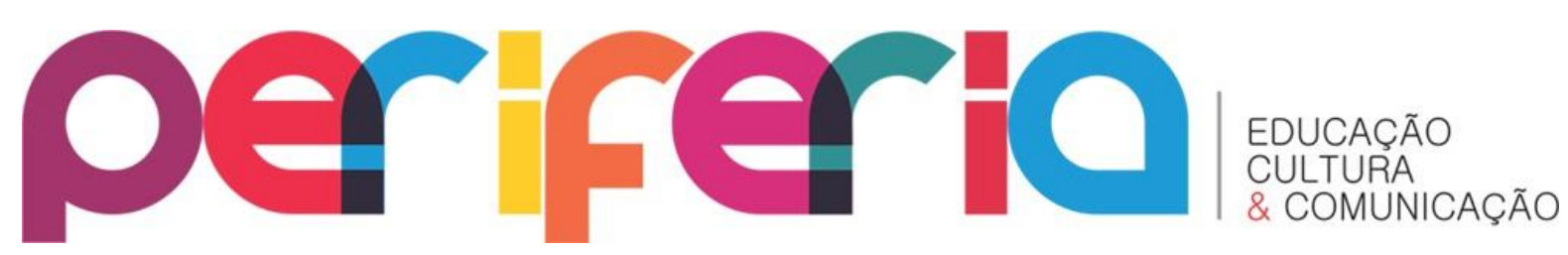

religiosidades e tantos outros, todos também híbridos em suas próprias constituições. É um espaço-tempo em que os bens simbólicos são "descolecionados", "desterritorializados", "impurificados", num processo que explicita a fluidez das fronteiras entre as culturas do eu e do outro e torna menos óbvias e estáticas as relações de poder (MACEDO, 2006, p.290).

Nesse sentido, apesar do currículo operar como um dispositivo de controle, e marcadamente controlado, ele é também o espaço-tempo no qual os sujeitos envolvidos se articulam, disputam poderes, subvertem os esquemas binários e recriam os sentidos do próprio discurso da escola. Nessa perspectiva, o currículo deve ser compreendido como ato de significação da própria cultura, como um discurso que constrói sentidos e que os dissemina. É entendendo o currículo do modo como Macedo (2006) o coloca, como um "espaço-tempo cultural liminar" entrecortado pelos embates, pelas negociações, pelo poder - que tanto serve para afirmar posições, quanto para deslocá-las - que faz sentido discutir as delicadas relações dos currículos escolares com a diferença. Embora os questionamentos sobre a necessidade e sobre as formas de abordagem ou incorporação da diferença aos currículos escolares tenham proliferado nas pesquisas e nos debates empreendidos no campo educacional (principalmente a partir da década de 1990), penso que ainda existem indagações importantes que tem a ver, sobretudo, com os sentidos que a diferença tem assumido nos discursos escolares. Como sustentar um discurso da diferença quando as próprias estratégias de lidar com ela incluem a sua nomeação e, consequentemente, a sua descrição e inscrição em categorias linguísticas culturalmente reconhecíveis? Como desconstruir as práticas de hierarquização que defendem a superioridade dos "iguais" sobre a inferioridade dos "diferentes"?

Sendo assim, não apenas o currículo escolar e a escola, mas também o currículo e a instituição escola, corroboram a produção de corpos, gêneros e sexualidades. O currículo escolar marca a experiência da escolarização como um dispositivo impregnado de tecnologias de controle da sexualidade, sobremaneira na infância. 0 efeito disso é uma sexualidade educada, na qual mesmo os sujeitos "transgressores" agem a partir de uma padronização, pela assimilação de comportamentos e condutas 


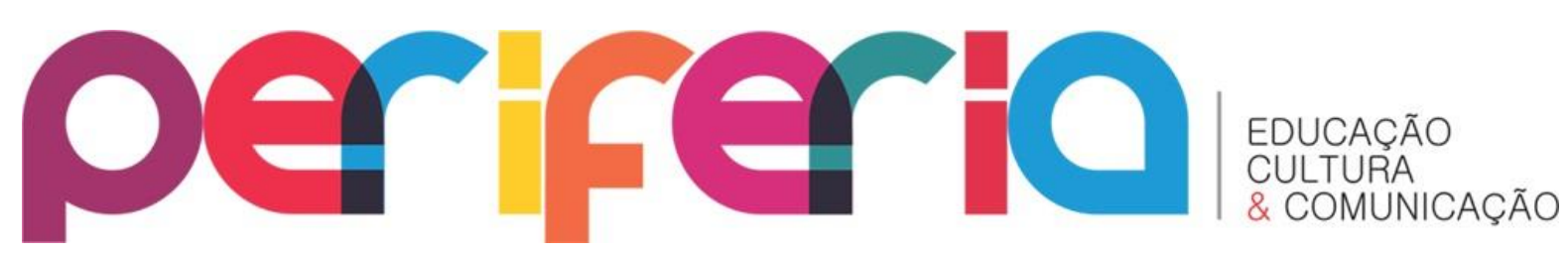

apropriadas, domesticadas. A pedagogia escolar está voltada à produção de homens e mulheres que ratifiquem a normalidade dominante, de acordo com o ideal de masculino e de feminino e funciona para dizer o que é certo, o que é bom, o que é normal - fundada na lógica binária classificatória e hierarquizante.

Nessa lógica, o dispositivo da sexualidade impõe modelos dados de existência corporal (homem e mulher), apresentando apenas duas opções nas quais os sujeitos devem se conformar (masculino e feminino) e uma única sexualidade legítima (heterossexualidade). Assim, não estar de acordo com as normas significa perder a representação nos quadros de legitimidade e de importância no/do espaço social (BUTLER, 2003).

A partir das narrativas de sujeitos transexuais, busco problematizar os processos de silenciamento, invisibilização e subalternização a que são submetidas por estarem identificadas como "diferentes" e discutir a deslegitimação dos seus "corpos estranhos". A seguir, trago as narrativas de Everlin, de Luciana e de Fernanda, mulheres transexuais cuja experiência pode ser produtiva ao enfrentamento das exclusões a que estão submetidos sujeitos que, como elas, vivem "fora" do espaço de inteligibilidade social.

\section{EVERLIN}

"Eu era uma coisa que eu não sabia nomear"

Eu nunca me senti homossexual, do grupo dos homossexuais. Tipo assim, eu comecei a me sentir diferente, eu não era homossexual, era uma outra coisa que eu não sabia nomear o que. Eu lembro que quando eu era criança eu fiquei sabendo que se alguém passasse por debaixo de um arco-íris trocava de sexo, aí quando eu via um arco-íris eu vivia correndo atrás do arco-íris. Então eu tinha essa fantasia infantil de que se passasse por debaixo do arco-íris trocava de sexo, então eu queria trocar de sexo!

[Na época da faculdade] eu fui chegando num ponto que eu fui ficando vestido de mulher o final de semana inteiro: sexta, sábado e domingo. Chegava segunda-feira é que eu vestia roupa de homem, porque aí eu não vinha para a sala de aula vestido de mulher. Primeiro porque eu tinha medo de não conseguir formar... Se eu tivesse virado travesti durante o curso provavelmente eu não tinha 


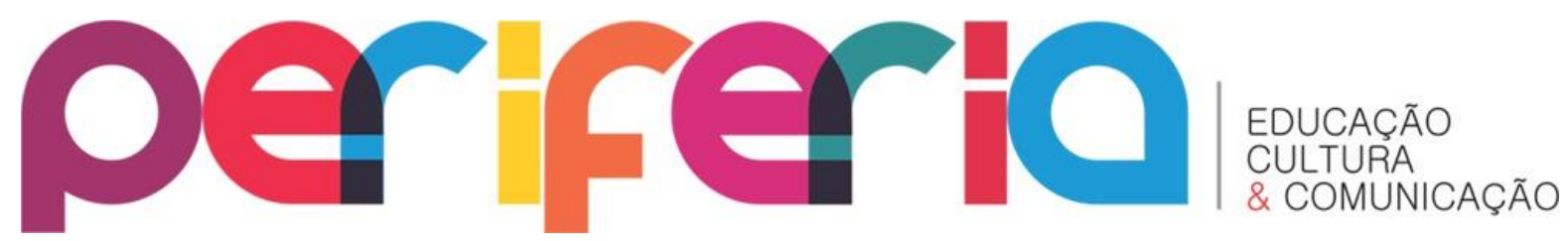

formado, acho que eles tinham arrumado um jeito de me dar bomba em alguma disciplina, dado um diagnóstico de loucura...

"Efeminado, mas de terno"

Eu tinha que procurar aula, dar aula, eu tinha que procurar ganhar dinheiro, então eu dei aula no ensino fundamental numa escola estadual. Eu peguei aquela designação temporária, peguei aulas de ciências. Aí eu dei aula... Só que eu ia de terno. Eu era assim, aquele professor efeminado, mas de terno. Porque eu senti que o terno me daria mais respeito ali naquele ambiente. Então eu dei durante dois meses, aula de terno, de roupa social. Aí eu lembro que eu fui dar aula num cursinho pré-vestibular, de português. Eu lembro que eu estava dando a aula e, na metade da aula, o segurança falou que era para eu parar a aula. Eu não entendi por quê... Quando foi três horas da tarde a diretora me chamou e falou: "Olha, é o seguinte: você é muito delicado, então eu acho que você não serve para dar aulas aqui. Os alunos estão querendo um professor mais enérgico, mais elétrico. Você é muito delicado, acho que você não vai servir para trabalhar." Então eu senti que, enquanto homossexual efeminado, eu já era discriminado no mercado de trabalho. Não adianta estar de terno, depois que abriu a boca e desmunhecou, queimou o filme. Então eu sentia isso, que eu tinha dificuldade de me inserir no mercado de trabalho por conta da minha orientação sexual. E, quando eu virei travesti, aí é que piorou.

\section{LUCIANA}

\section{"É como se a gente fosse uma errada no meio de todo mundo"}

Desde 5 anos de idade que eu tinha essa concepção na minha cabeça: que eu não era um menino. Eu me olhava no espelho e eu não via um menino. Eu olhava e pensava o seguinte: não sou eu! Eu olhava e falava: "Não, não sou eu ali. Aquela pessoa ali de cabelo curto... Não sou eu." Na minha cabeça eu lembro sempre que eu me senti uma mulher, sabe? E fantasiava na minha cabeça... Na minha ideia é como se eu criasse um mundo paralelo pra conseguir ir levando as coisas. Na minha condição a gente sente assim, na escola, como se a gente fosse uma errada no meio de todo mundo - as coisas não são feitas pra você ali, entendeu? As coisas são feitas para o menino e para a menina. Por exemplo, a educação física mesmo era um tormento. Eu nunca tive vontade de jogar bola, essas coisas assim. Trocar de roupa perto dos meninos? Isso pra mim é como se fosse... Era uma tortura, você entendeu? E, assim, a gente começa a desenvolver certos mecanismos de defesa, a gente fica assim: "Se eu conversar sobre alguma coisa, eu vou ser ridicularizada..." 


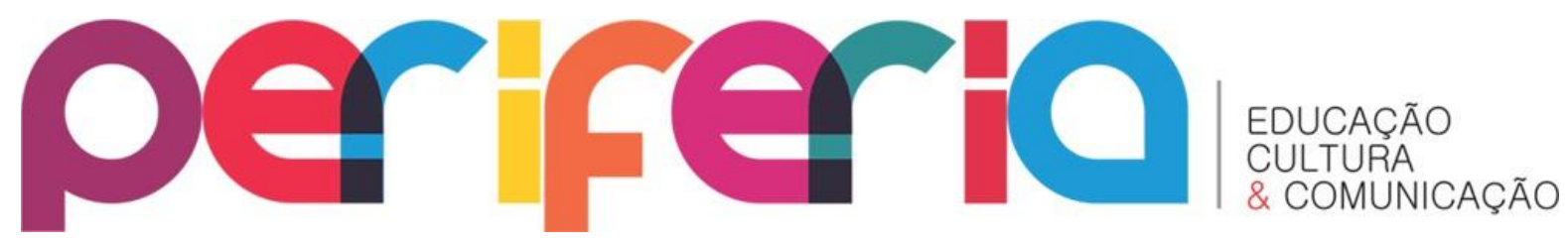

Eu era uma pessoa muito prestativa, muito inteligente - eu fazia as coisas direitinho, e isso, tipo assim, atraia as pessoas. Talvez seria até uma forma de... como é que eu posso explicar? De contornar, ir levando a situação. Aí a dificuldade que eu tinha era a hora de recreio... eu ficava quietinha, porque eles olhavam... sempre me apontavam: "Aquele menino, não sei o que... é esquisito!" E quando isso acontecia eu ficava muito triste, aí eu me retraia, mas ficava assim: "Ah, meu Deus, eu não tenho culpa disso."

$\mathrm{Na}$ escola esse assunto e outras coisas nem fala... E, no meu caso, que é a transexualidade, na época eu nem ouvia, você nem sabia o que queria dizer isso - era gay, essas coisas... E aí que vem um mundo de informação na sua cabeça, aquele mundo de coisas que agora você não vai conseguir arrumar emprego, que as pessoas vão te maltratar, isso, isso e isso. Igual uma vez quando o professor comentou que as tribos indígenas hoje já estão tão diferentes, que tem até índio - e ele fez com a mão assim (mostra a mão "desmunhecada", típico de como se representa, estereotipadamente, o homossexual masculino) - índio virando gay. Aí nessa hora você fica meio perdido: "Tomara que ninguém olhe pra mim." Porque você se sente o alvo, é sempre por causa daquela coisa que você é...

\section{"Se você não pode ser bom, pelo menos seja cuidadoso"}

Eu sempre me tratava por ela. Mas inconscientemente, porque eu não podia comentar com ninguém. Aí as lembranças que eu tenho é que, às vezes, professores, até de ciências mesmo, quando tratavam do assunto tratavam de forma debochada e eu me sentia uma anormal no meio desse pessoal, né? Eu nunca tive coragem de falar nada, parece que fica uma coisa tão velada... as pessoas acho que fingem não ver nada: "não é da minha conta" e você finge que não vê.

Eu evitava discutir com os outros com medo deles me jogarem isso na minha cara, porque isso era uma arma que a pessoa tinha contra mim. Aí tentava fazer as coisas... Tentava ser a boazinha, ser a prestativa... Talvez era até uma certa forma de sobreviver, de me proteger. Aí a companhia que eu tinha era a televisão, era onde eu pegava informação. Ali eu descobria coisas diferentes, via como que eram as coisas, gostava muito de estrelas de cinema e ficava fantasiando que eu era uma delas. Assim eu conseguia ir levando as coisas. Eu não era de ficar triste. E também sempre respeitei os colegas de sala, ninguém pode falar: "Ela já deu em cima de mim." Nunca! Nunca dei em cima de ninguém. Parece que Deus me deu uma certa inteligência para lidar com as coisas. Então nunca eles 


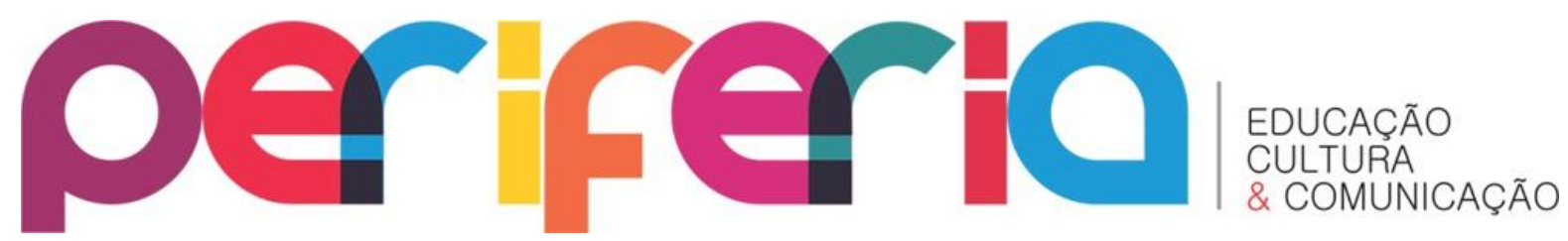

podem falar que eu cantei, dei em cima, porque, talvez, eles tenham muito medo disso. "Se você não pode ser bom, pelo menos seja cuidadoso"... Era isso que eu fazia, tinha muito cuidado de lidar com as coisas.

"As professoras primeiro não falavam nada, fingiam que não tinham escutado"

Eu sempre fui o mais arrumado, tinha o material todo que mãe comprava, estudava, sabia conversar, era o mais queridinho das professoras. As professoras viviam falando: "Todo limpinho, todo arrumadinho... Olha que bonitinho que ele é. Vocês deviam seguir o exemplo." No começo ninguém respondia. Depois começaram a tirar sarro: "Cruz-credo! Não quero ficar igual esse viadinho, não." As professoras primeiro não falavam nada, fingiam que não tinham escutado, mas depois, eu acho que elas começaram a ficar incomodadas. Mandavam os meninos calarem a boca. Eles calavam na hora - na frente da professora - mas depois ferviam a me xingar de mulherzinha, de bichinha, de viado. Eu nunca falei nada, nunca reclamei com a professora, acho que eu já sabia que era verdade. Aí comecei a ficar bem quieto, não queria mais falar na sala, nem mostrava os exercícios, não queria participar de nada.

Lá na escola as professoras já tinham acostumado comigo, então nem se importavam mais com as piadas, com as brincadeiras dos outros. Eu também não falava nada, aprendi que ficando calada eles perdiam um pouco a graça de mexer comigo. O problema foi quando eu tinha uns 12 ou 13 anos... Porque aí eu comecei a querer ser mulher mesmo, implorei para mãe deixar meu cabelo crescer um pouco e ela acabou deixando, eu estava cada vez mais efeminado, mais parecendo menina que menino e comecei a apaixonar pelos meninos da sala. Lembro que um dia a professora mandou fazer uma redação contando de um sonho que a gente tinha e eu falei que queria casar com um príncipe. Na hora de ler lá na frente da sala eu li e todo mundo caiu na risada. A professora, acho que querendo ajudar, falou assim: "Você quer dizer que quer casar com uma princesa, não é?" Aí eu falei: "Não. Quero casar com um príncipe." Aí ela ficou calada e mandou outro aluno ler a redação dele. Não falou mais nada, mas me deu um bilhete para levar para casa. Hoje, lembrando disso, eu sei que ela mandou minha mãe me levar ao psicólogo, porque mãe chamou minha irmã e as duas foram comigo no tal psicólogo na outra semana. Eu odiei ir ao psicólogo. Ele fazia as perguntas e eu ficava caladinha. Fui lá umas três vezes e não abri a boca. Aí o psicólogo falou com mãe que eu não estava pronto para fazer o tratamento. Mãe ficou aborrecida e falou: "Meu filho não é 


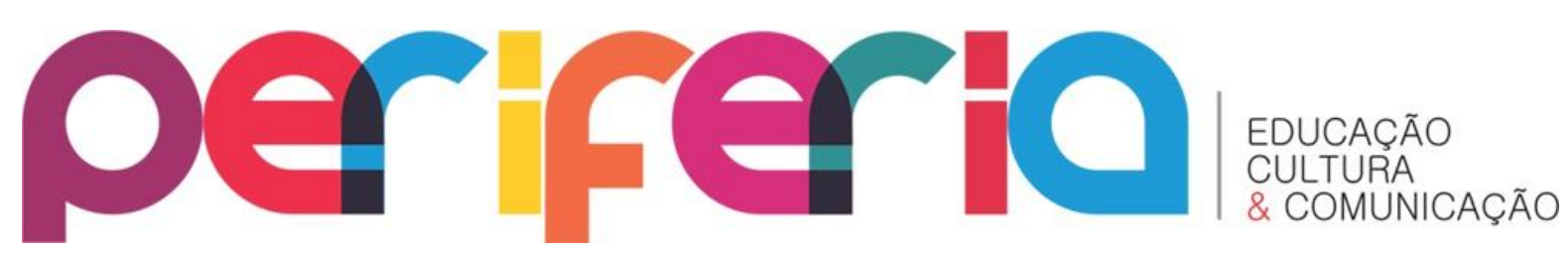

doido, não precisa de fazer tratamento. Ninguém entende que ele é assim porque perdeu o pai muito novo, não teve influência de homem quando era pequeno."

As falas das entrevistadas revelam um sentimento de inadequação, de estarem "fora" da sociedade, de serem identificadas por uma sexualidade "contra a natureza" e, como tal, justificam (até mesmo para si) as discriminações sofridas: "Eu nunca falei nada, nunca reclamei com a professora, acho que eu já sabia que era verdade" (Fernanda). Suas falas dão conta das exclusões provocadas a partir de alguns saberes sobre as sexualidades não-normativas que constituem o imaginário social e instituem sujeitos, mantendo e reproduzindo estigmas e estereótipos.

A partir dessas narrativas, sublinho duas questões que passo a discutir: a) a manutenção de determinado padrão de masculinidade e de feminilidade que norteia a produção dos corpos; b) a transexualidade como produto de um desejo sexual desviante e anormal e, por ser um ato "contra a natureza", justifica a exclusão e a ação de determinados mecanismos de controle.

\section{a) $\mathbf{O}$ corpo gendrado}

A rigidez dos "papéis" ${ }^{2}$ de homem e de mulher, ainda presente na sociedade, produziu e fixou a oposição binária entre masculino e feminino. Uma das considerações comumente afastada por essa forma polarizada de pensar o gênero são as fragmentações e descontinuidades internas de cada um, ou seja, as diferentes posições dos sujeitos masculinos e femininos em relação às suas marcas identitárias e aos seus processos de identificação particulares e descontínuos.

Desconstruir os gêneros tal qual uma totalidade unificada implica em rever os conceitos de masculinidade e de feminilidade, repensar a própria ideia de sexualidade que prevaleceu por muito tempo como derivada da combinação binária dos gêneros e as sexualidades não-normativas como uma deformação que altera a "essência" do humano, promovendo que os sujeitos se identifiquem sexualmente com o "papel" do

\footnotetext{
${ }^{2}$ Trabalho com a ideia comumente associada ao uso do termo, neste contexto, que visa enunciar que há certo repertório de condutas, comportamentos, modos de vida próprios e exclusivos para homens e para mulheres que devem ser aprendidos e desempenhados nas relações sociais.
} 


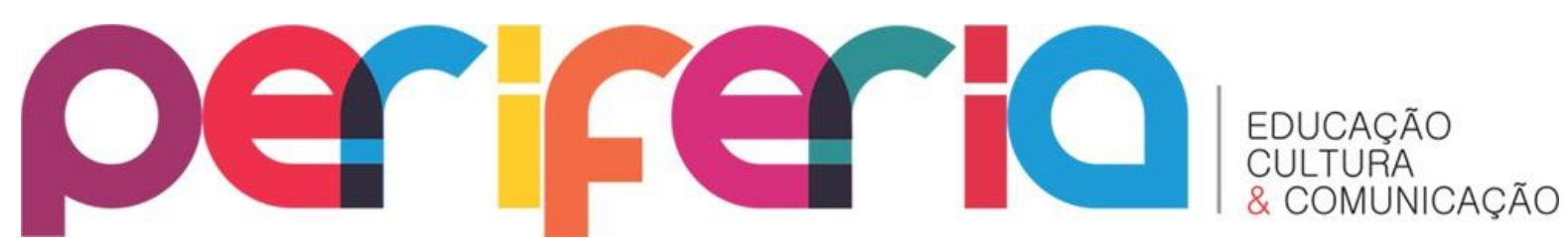

outro gênero. Ou, da forma que expressa Everlin, situem-se em um espaço ainda não existente porque não podem ser traduzidas na linguagem: "Eu era uma coisa que eu não sabia nomear".

Desse modo, embora os discursos já tenham avançado, principalmente nos meios acadêmicos, ainda é recorrente e visível que determinados "papéis" de homem e de mulher nutram os imaginários e as representações sociais, inclusive as dos próprios sujeitos transexuais. Espera-se, dessa forma, que meninos e meninas sejam educados para repetir/assumir os "papéis" que Ihes cabem na dinâmica social. Desde pequenos, escola e família (como também outras instituições sociais) colaboram entre si para tornar essas crianças os homens e as mulheres que eles e elas devem ser. Adquirindo os gostos, expressões, comportamentos próprios/apropriados de um ou de outro sexo biológico.

Assim como a correta construção dos gêneros, tarefa atribuída a si pelos adultos, a sexualidade da criança constitui também uma preocupação, à medida que garantiria a estabilidade das posições de homem e de mulher e, consequentemente, a heterossexualidade normativa. Conforme afirma Louro “(...) a vigilância e a censura da sexualidade orientam-se fundamentalmente, pelo alcance da 'normalidade' (normalidade essa representada pelo par heterossexual, no qual a identidade masculina e a identidade feminina se ajustam às representações hegemônicas de cada gênero)" (2001, p.80).

Faz sentido, portanto, que a transexualidade, ao transgredir a "natureza" marcada no corpo (nascer com pênis/nascer com vagina), figure como um desvio na construção do gênero. Disso resulta a ideia de que é possível atuar, por meio de estratégias pedagógicas, médicas e psicológicas de correção a fim de reimplantar a sexualidade - como heterossexualidade - nos corpos dos sujeitos. Estudos como os de Camargo (1999); Altmann(1998); Sousa (1984) e Louro (1992) apontam estratégias de policiamento na construção do gênero realizadas pelas pela escola que buscam regular e normalizar a sexualidade pela fiscalização dos processos de identificação de sexo e gênero, pela fixação dos limites do corpo e pela naturalização da 


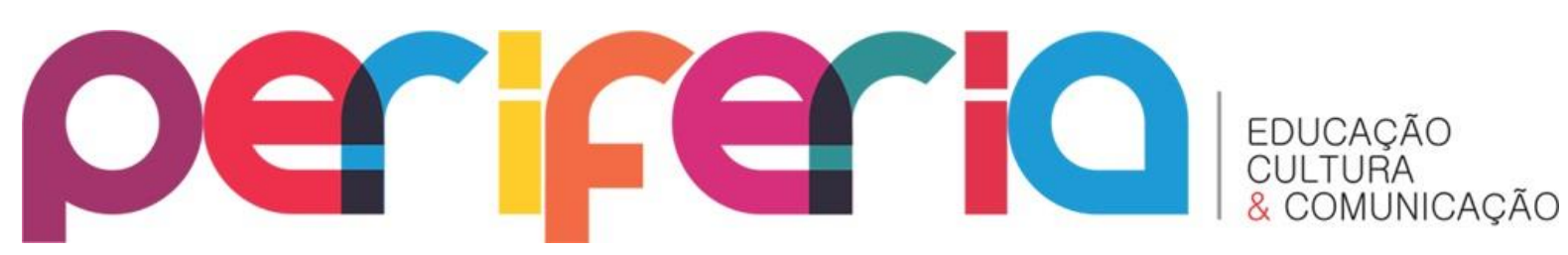

heterossexualidade. Os estudos demonstram, ainda, que tais estratégias não têm produzido os efeitos esperados, instaurando a perplexidade entre os sujeitos poucos aptos a lidar com as questões que extrapolam os limites seguros e estáveis dos ordenamentos (corpo-sexo-gênero-desejo-práticas sexuais) e binarismos existentes (homem/mulher; masculino/feminino; ativo/passivo; heterossexual/homossexual). Tal como expresso nas narrativas desses sujeitos, se evidencia que:

O grande desafio não é apenas assumir que as posições de gênero e sexuais se multiplicaram e, então, que é impossível lidar com elas apoiadas em esquemas binários; mas também admitir que as fronteiras vêm sendo constantemente atravessadas e - o que é ainda mais complicado - que o lugar social no qual alguns sujeitos vivem é exatamente a fronteira. (...) as certezas escapam, os modelos mostram-se inúteis, as fórmulas são inoperantes. (...) Não há como ignorar as "novas" práticas, os "novos" sujeitos, suas contestações ao estabelecido (LOURO, 2004, p. 28-29).

$\mathrm{Na}$ condição de Everlin, Luciana e Fernanda se encontram também outros sujeitos que, para escapar da marginalidade e da exclusão, são levados a despojar-se de si por meio de um processo disciplinador, geralmente condicionado à alienação do desejo e das identificações pessoais. Muitas vezes, para escapar dos efeitos da sua "estranheza" nos espaços sociais comuns, esses sujeitos acionam estratégias de apagamento da diferença, adequando-se ou simulando a normalidade vigente, movimentando-se de acordo com os códigos aceitos e legitimados na/da sociedade em questão: Everlin usava um terno, Luciana era sempre boazinha e prestativa, Fernanda aprendeu a ficar calada.

Nas experiências narradas, pelo menos por algum tempo, essas estratégias de apagamento da diferença como condição ao pertencimento social demonstraram ser passíveis de sucesso. O lado mais perverso desta "opção" pela ausência de uma representação própria de si é que ela mantém a condição de subalternidade quando exige que esse outro abdique de seus traços identitários em favor de uma identidade que se impõe como a única legítima e importante. 


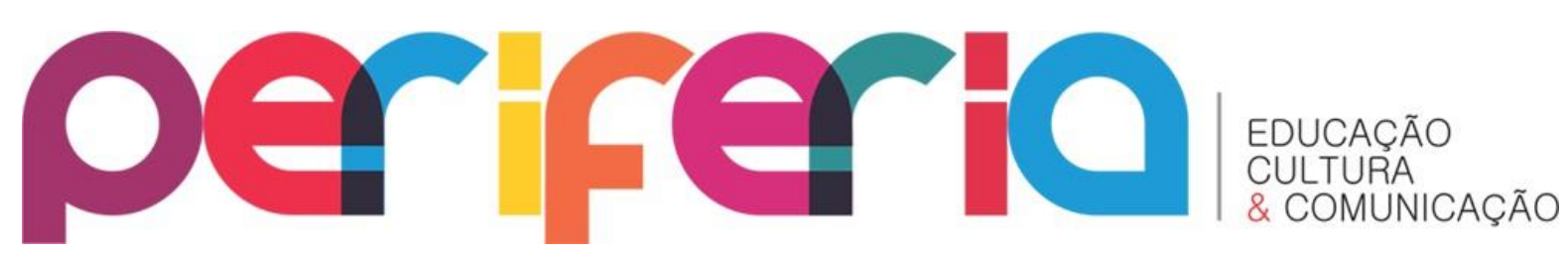

\section{b) $O$ dispositivo da heterossexualidade e a fabricação do anormal}

Como saída à experiência restritiva do sexo na sociedade - e às intensas discriminações e cerceamentos políticos de que são alvos os sujeitos que não conseguem/podem/desejam inscrever-se na esfera da inteligibilidade social - Butler (2003) enfatiza a necessidade de rompimento com o sistema binário que corrobora a relação mimética entre gênero e sexo, ao afirmar que o primeiro está determinado pelo segundo. Para tanto, a autora instiga a construir outra forma de pensamento na qual o corpo deixe de ser um meio passivo sobre o qual se inscrevem os significados culturais e passe a ser pensado também como uma produção performativa ${ }^{3}$.

A autora argumenta que para operar essa produção performativa é indispensável que as normas que regulam e materializam o sexo e o gênero sejam continuamente repetidas, sempre amparadas por/em instituições e sujeitos detentores de uma autoridade reconhecida como legítima. Nesse mesmo sentido, Butler (2003) aponta que a fixação da "matriz heterossexual" se dá com base na linearidade e na invariância da sequência corpo-sexo-gênero-desejo e prática sexual.

Essa matriz excludente, ao mesmo tempo em que afirma a heterossexualidade normativa como a sexualidade possível, cria a rejeição aos sujeitos que não se apresentam coerentemente gendrados: aos "esquisitos", como narra Luciana. Assim, para se inscrever como legítimo, como um "corpo que importa", o sujeito se verá obrigado a obedecer às normas de sua cultura: "Eu era assim, aquele professor efeminado, mas de terno. Porque eu senti que o terno me daria mais respeito ali naquele ambiente".

3 Butler (2003) assinala que o gênero não pode ser entendido apenas como algo que se consolida mediante a heterossexualidade normativa, antes como uma produção sustentada pela repetição de práticas que acabam por ser naturalizadas por vários dispositivos, tais como as normas gramaticais, os habitus generificados e os binarismos que alimentam a fixação de categorias a partir da noção que há uma essência interna ditada pelo sexo biológico. Para Butler, o gênero se produz por meio de um processo performativo, ou seja, pela repetição constante das normas que regulam os corpos, sexos e gêneros visando à fabricação de uma materialidade desejável, legítima. Nesse sentido, o gênero é pensado como uma imitação persistente, que passa como real e, no entanto, é a própria repetição da norma ocasiona a sua ressignificação e a sua proliferação para além da estrutura binária (masculino/feminino). 


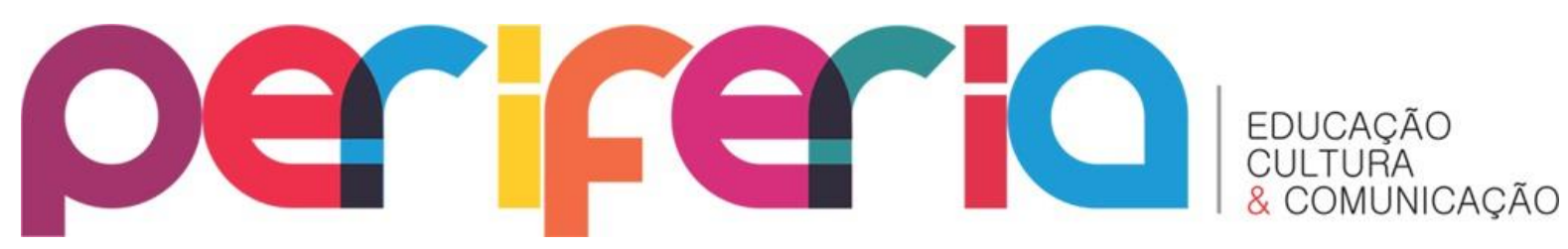

No entanto, a repetição das normas constitutivas da inteligibilidade heteronormativa torna-se ela mesma uma repetição subversiva, pois, ao forçar a repetição, também se produz possibilidades de vida que não apenas ultrapassam os limites, como efetivamente expandem as fronteiras do que é culturalmente inteligível. Desse modo, as mesmas regras que restringem também mobilizam formas alternativas de vida que contestam as classificações, as hierarquias e os códigos existentes fazendo multiplicar as configurações do corpo, do sexo, do gênero, da sexualidade. Destarte ainda que atue como um regime regulador - e exatamente por isso - a heterossexualidade normativa opera na sua própria desnaturalização, pois “(...) embora gênero e subjetivação sejam reiterações da norma sexual, na própria instabilidade da repetição do mesmo é possível vislumbrar a positividade da subjetivação como resistência, singularidade e produção da diferença" (ARÁN \& PEIXOTO JÚNIOR, 2007, p. 129).

Nesse sentido a subversão não é uma força evidente de oposição à norma que se situa fora dela, pois não se trata de uma luta declarada e transparente, mas de uma operação ambivalente que age no interior, produzindo deslocamentos e colocando em questão a própria originalidade e completude da norma a ser repetida. A exclusão subjacente a esse processo não é, portanto, produzida fora da norma, antes produzida e mantida dentro dela: a criação do "anormal" é, ao mesmo tempo, efeito da repetição da norma e condição do seu funcionamento. É em relação a esse "anormal” que faz sentido pretender instaurar, ratificar, validar a norma.

O trabalho de Butler (2003) afirma que a lógica binária está fundada na determinação de posições eu/outro, nós/eles na qual o outro aparece sempre em desvantagem, um outro que, como diz Luciana "é um errado no meio de todo mundo". É nesse espaço de oposição, como outro de um discurso naturalizante e normalizador que se encontram as entrevistadas: seus corpos rearranjados por meio de técnicas cirúrgicas e de medicamentos extrapolam os limites convencionais, escapam à inteligibilidade, vivem dentro dos discursos como figuras não questionadas, indistintas, como se não tivessem conteúdo ou se não fossem reais, mas que, ainda assim, 


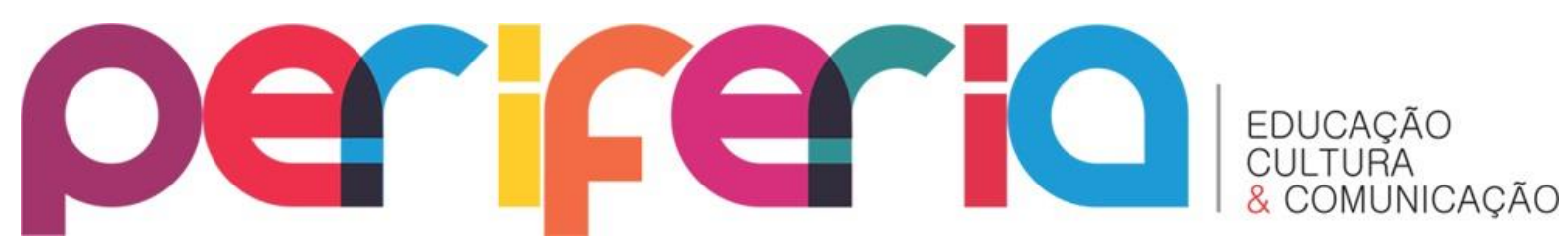

produzem outras estéticas, outros prazeres, outras formas de ser — ou de não ser homens e/ou mulheres.

Assim, por não ter o reconhecimento social como heterossexual efetivo, esses sujeitos perdem uma identidade social possível em troca de uma que é radicalmente menos sancionada (BUTLER, 2003, p. 116-117). Uma operação que gera medo e desconfiança, como narra Everlin:

Chegava segunda-feira é que eu vestia roupa de homem, porque aí eu não vinha para a sala de aula vestido de mulher. Primeiro porque eu tinha medo de não conseguir formar... Se eu tivesse virado travesti durante o curso provavelmente eu não tinha formado, acho que eles tinham arrumado um jeito de me dar bomba em alguma disciplina, dado um diagnóstico de loucura...

Uma forma de vida que exige um excessivo controle de sua presença, do que está ou pode ser visível ao outro:

Parece que Deus me deu uma certa inteligência para lidar com as coisas. Então nunca eles podem falar que eu cantei, dei em cima, porque, talvez, eles tenham muito medo disso. "Se você não pode ser bom, pelo menos seja cuidadoso"... era isso que eu fazia, tinha muito cuidado de lidar com as coisas. (Luciana).

As discriminações negativas, os estigmas e os estereótipos constituintes das histórias de Everlin, Luciana e Fernanda expressam a nossa limitada capacidade de conviver com a diferença, sobretudo quando ela transparece na exterioridade da pele e, portanto, não pode ser ocultada. Quando a diferença em questão refere-se à transexualidade as dificuldades se acentuam, principalmente porque se relacionam às pessoas cuja posição está fixada no imaginário social como sujeitos que transgridem e, portanto, ameaçam a ordem normativa, as convenções sociais do corpo, do gênero e da sexualidade. Suas experiências mostram o que é crescer como pessoa sem importância, obrigada a sustentar a perigosa visibilidade dos seus corpos e de seus desejos ou a ocultar sua incômoda diferença - invisibilizando-se nas relações sociais cotidianas.

Importante assinalar as estratégias desses sujeitos para conviver com seus estigmas, escondê-los, minimizar seus efeitos ou suplantá-los: 


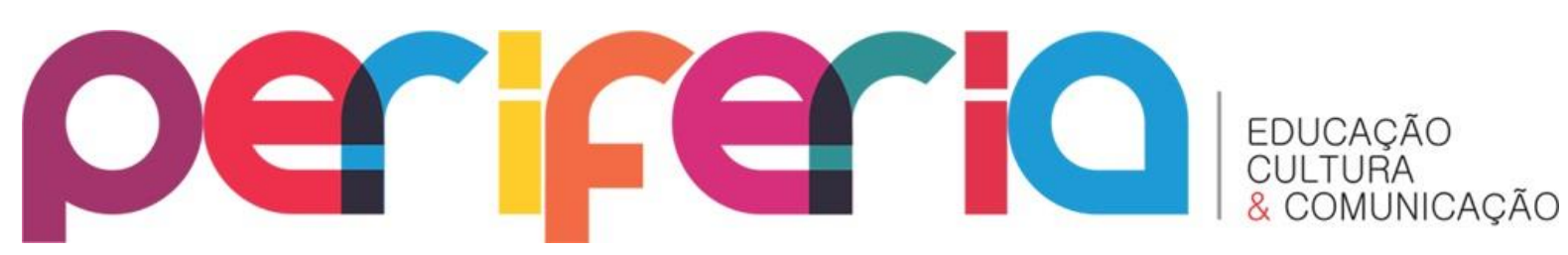

Eu evitava discutir com os outros com medo deles me jogarem isso na minha cara, porque isso era uma arma que a pessoa tinha contra mim. Aí tentava fazer as coisas... tentava ser a boazinha, ser a prestativa... (Luciana).

Ter contato com as narrativas desses sujeitos aponta a urgência de indagar as representações aceitas (e repetidas) que frequentemente habitam o interior da escola e possibilitar inscrições de novos/outros modos de vida nos contextos escolares e nos demais espaços sociais comuns. A pista que acredito ser produtiva seguir diz respeito ao trabalho necessário de desnaturalização das identidades de gênero e sexuais, provocando o rompimento com a heteronormatividade e criando condições para a emergência de novos/outros corpos, como "corpos que importam", que têm valor. Os esforços de entendimento e os questionamentos das significações produzidas devem servir para ampliar os espaços nos quais os sujeitos possam ter reconhecidos os seus corpos, suas sexualidades, seus estilos de vida e reclamar contra a exclusão de sujeitos cuja própria humanidade apenas é reconhecida quando a condição humana não se encontra fechada em categorias previamente descritas e nomeadas (BUTLER, 2006).

\section{REFERÊNCIAS BIBLIOGRÁFICAS}

ALTMANN, Helena. Orientação sexual nos Parâmetros Curriculares Nacionais. Revista de Estudos Feministas, Florianópolis, v.9, n.2, 201, 1998. p. 576-585.

ÁRAN, Márcia; PEIXOTO JÚNIOR, Carlos Augusto. Subversões do Desejo: sobre gênero e subjetividade em Judith Butler. Cadernos Pagu. Campinas, Núcleo de Estudos de Gênero Pagu, v.28. jan/jun 2007. p. 129-148.

BHABHA, H. K. O local da cultura. Tradução de Myriam Ávila, Eliana L.L. Reis e Gláucia R. Gonçalves. Belo Horizonte: Editora UFMG, 2007.

BUTLER, Judith. Cuerpos que importan. Sobre los límites materiales y discursivos del "sexo". Buenos Aires: Paidós, 2006.

BUTLER, Judith. Problemas de gênero. Feminismo e subversão da identidade. Rio de Janeiro: Civilização Brasileira, 2003.

CAMARGO, Ana Maria F.; RIBEIRO, Cláudia. Sexualidade(s) e infância(s): a sexualidade como um tema transversal. São Paulo: Moderna e Campinas: Ed. da Unicamp, 1999

CARVALHO, Mauro Giffoni de. Sexualidades em psi-maior: identidades sexuais e contemporaneidade. Belo Horizonte: Pulsar, 2003.

FOUCAULT, M. Verdade e Poder. In: Microfísica do Poder. Rio de Janeiro: Edições Graal, 2004. 


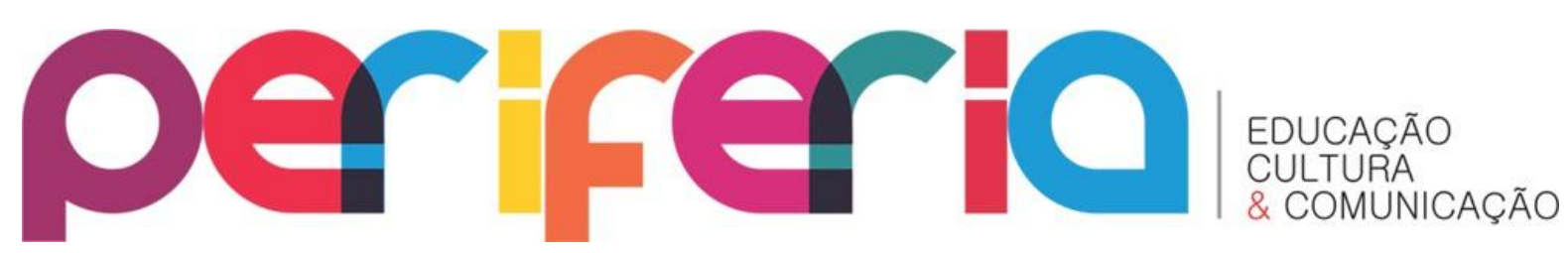

FOUCAULT, Michel. As palavras e as coisas. São Paulo: Martins Fontes, 2000.

GOODSON, I. F. Currículo: teoria e história. Trad. Attílio Brunetta. 6. ed. Petrópolis: Vozes, 2003. (Ciências sociais da educação).

GOFFMAN, Erving. Estigma: notas sobre a manipulação da identidade deteriorada. 4 ed. Rio de Janeiro, Guanabara, 1988.

HALL, Stuart. A identidade cultural na pós-modernidade.(trad. Tomaz Tadeu da Silva e Guacira Lopes louro). 7.ed. Rio de Janeiro: DP\&A, 2002.

LOURO, Guacira L. Teoria queer: uma política pós-identitária para a Educação. Revista Estudos Feministas, v. 9, n. 2, p. 541-553, 2001.

LOURO, Guacira Lopes. Uma leitura da história da educação sob a perspectiva de gênero. Teoria e Educação, n. 6. Porto Alegre, 1992, p. 53-67.

MACEDO, E. Currículo como espaço-tempo de fronteira cultural. Revista Brasileira de Educação, v.11, n.32, maio/ago. 2006. p.285-372.

MISKOLCl, Richard. Pânicos morais e controle social - reflexões sobre o casamento gay. In: Cadernos pagu, n.28, janeiro-junho de 2007, p.101-128.

PINO, Nádia Perez. A teoria queer e os intersex: experiências invisíveis de corpos desfeitos. In: Cadernos Pagu. Campinas, Núcleo de Estudos de Gênero Pagu, v.28. jan/jun 2007. p. 149-174.

SOUSA, Eustáquia Salvadora de. Meninos, à marcha! Meninas, à sombra! A história da educação física em Belo Horizonte (1897-1994). Tese de doutorado em Educação. Campinas: Unicamp, 1984.

VEIGA-NETO, A. De geometrias, currículo e diferenças. Educação \& Sociedade, Campinas, SP, n.79, 2002. p.163-186. 